\title{
Active tectonics around the Mediterranean region: site studies and application of new methodologies
}

\author{
Luigi Cucci ${ }^{1}$, Paolo Marco De Martini ${ }^{1}$, Eulalia Masana ${ }^{2}$, Kris Vanneste ${ }^{3}$ \\ ${ }^{1}$ Istituto Nazionale di Geofisica e Vulcanologia, Sezione Sismologia e Tettonofisica, Rome, Italy \\ ${ }^{2}$ Universitat de Barcelona, Departament de Geodinàmica i Geofisica, Barcelona, Spain \\ ${ }^{3}$ Royal Observatory of Belgium, Departament of Geodynamics, Section Seismology, Brussels, Belgium
}

More than 25 years have passed since the definition of Active Tectonics as "tectonic movements that are expected to occur within a future time span of concern to society", formulated in a milestone book by the National Research Council on this topic (Studies in Geophysics, Active Tectonics, National Academy Press, Washington, D.C. 1986), and those words have still to be considered the most suitable and exhaustive way to explain this branch of the Earth Sciences. Indeed only bridging together basic studies ("tectonic movements"), rates of occurrence ("time span") and hazard assessment ("society") can we fully evaluate ongoing tectonic activity and its associated hazards. The broad Mediterranean Sea region is a paradigmatic area from this point of view, as on one hand this region displays in a relatively limited geographic extent a great variety of tectonic processes such as plate collision, subduction, volcanic activity, large-magnitude earthquakes, active folding and faulting, vertical uplift and/or subsidence. On the other hand, all the above mentioned tectonic processes can potentially affect a total population of about 450 million, mostly concentrated in fast-growing urban areas and/or close to industrial compounds and critical facilities often located nearby hazard sources.

On this basis we introduce this special volume of Annals of Geophysics named Active tectonics around the Mediterranean region: site studies and application of new methodologies, in which seven papers illustrate the ongoing tectonic activity in a number of key areas of the Mediterranean region, and try to evaluate rates, styles and patterns of deformation through the application of modern methodologies. The figure below provides in a unique view the papers presented, the areas investigated, and the techniques adopted. The scale of observation of the different contributions is extremely diverse, passing from the $\mathrm{km}$-wide local extent of trenching sites to the $1500 \mathrm{~km}$-long Africa-Eurasia plate boundary, attesting the potential and the versatility of the methodologies used, which include a combination of geological, geophysical, seismological and geodetic studies.

Some of these techniques, such as field geology (structural geology, Quaternary stratigraphy, sedimentology) and seismology (earthquake location, focal mechanisms, modeling of earthquake occurrence), have been the only tools available to the scientific community for decades, and provided basic data, observations and concepts at the early stages of the research in active tectonics. Other complementary techniques that were developed during the last decades of the past century, leading to some new insights about active tectonics, comprise paleoseismology, quantitative geomorphology, exploration geophysics, geodesy, new dating techniques, and modern computer resources.

Among these, paleoseismology has been rapidly established as one of the most important methodologies to reconstruct the seismic history at a given place. Studying location, timing, and size of past earthquakes by geological means, such as by microstratigraphy and microgeomorphology, on one side has improved our understanding of the seismic cycle, fault behaviour, and evolution of fault activity, and on the other side has provided an impressive number of new data that are essential to seismic hazard evaluation and long-term earthquake forecasting.

Quantitative geomorphology as well has developed into one of the most powerful means of investigation in active tectonic studies. The widespread availability of landforms such as marine terraces, river courses, fault scarps and mountain fronts, which can be extremely sensitive to tectonic forcing, usually provides remarkable understandings of rates, styles and patterns of the tectonic processes affecting a region.

Exploration geophysics, and specifically seismic reflection, represents the most common means of massive investigation beneath the land surface. Seismic reflection profiles provide fundamental help in clarifying the relationship between the surface expression of tectonic features and their deep structural setting, imaging faults, folds and displaced horizons. High resolution 3-D reconstructions obtained with this methodology contribute in evaluating the hierarchy between structures and in constraining (the amount of) Late Quaternary motion along seismogenic faults. 
Great amounts of data from geodetic techniques have been gathered in the past decades to delineate the patterns and scales of the ongoing deformation. Current plate movements, block rotations, crustal shortening and/or extension, and volcanic activity can be tracked directly by means of space-based geodetic measurements. Also, repeated geodetic measurements allow detecting present-day rates of fault slip and strain accumulation, providing insights into the characterization of the seismic deformation cycle. Geodesy offers the opportunity to collect a significant amount of data pertaining to the present-day situation, in close to real-time recording that allows a gain on details incomparable with respect to other methods. However, such a fine tuning over such a short geological time span might not be sufficient to identify the majority of tectonic movements and to determine their long-term rates.

This introduces adequate age control as the binding issue and the possibly limiting factor in active tectonics studies; each of the above described methodologies can provide remarkable results in identifying patterns of tectonic processes that are useless if not supported by necessary age constraints. Thus, for any active tectonic event it is crucial to determine its rate of occurrence, and to try to evaluate possible changes in this rate. Consequently, special attention to the issue of age control has been devoted throughout the papers presented in this volume.

Finally, in the past decades the value of databases and other computer resources from many fields of active tectonics research has dramatically increased. Although they cannot be strictly considered as a technique of investigation, databases provide homogeneous and standardized geological, historical and instrumental information. For instance, a database on the seismogenic sources of a given region is a useful basis for performing seismic hazard analyses.

In summary, earth scientists identify active tectonics features and evaluate their degree and patterns of activity, providing data that are the fundamental contributions for a more realistic assessment of the hazard, and constitute the basic step to guide the engineering community and policy makers in their actions to minimize the vulnerability and to mitigate the risk.

In the following we give a short presentation of the contributions to this special volume:

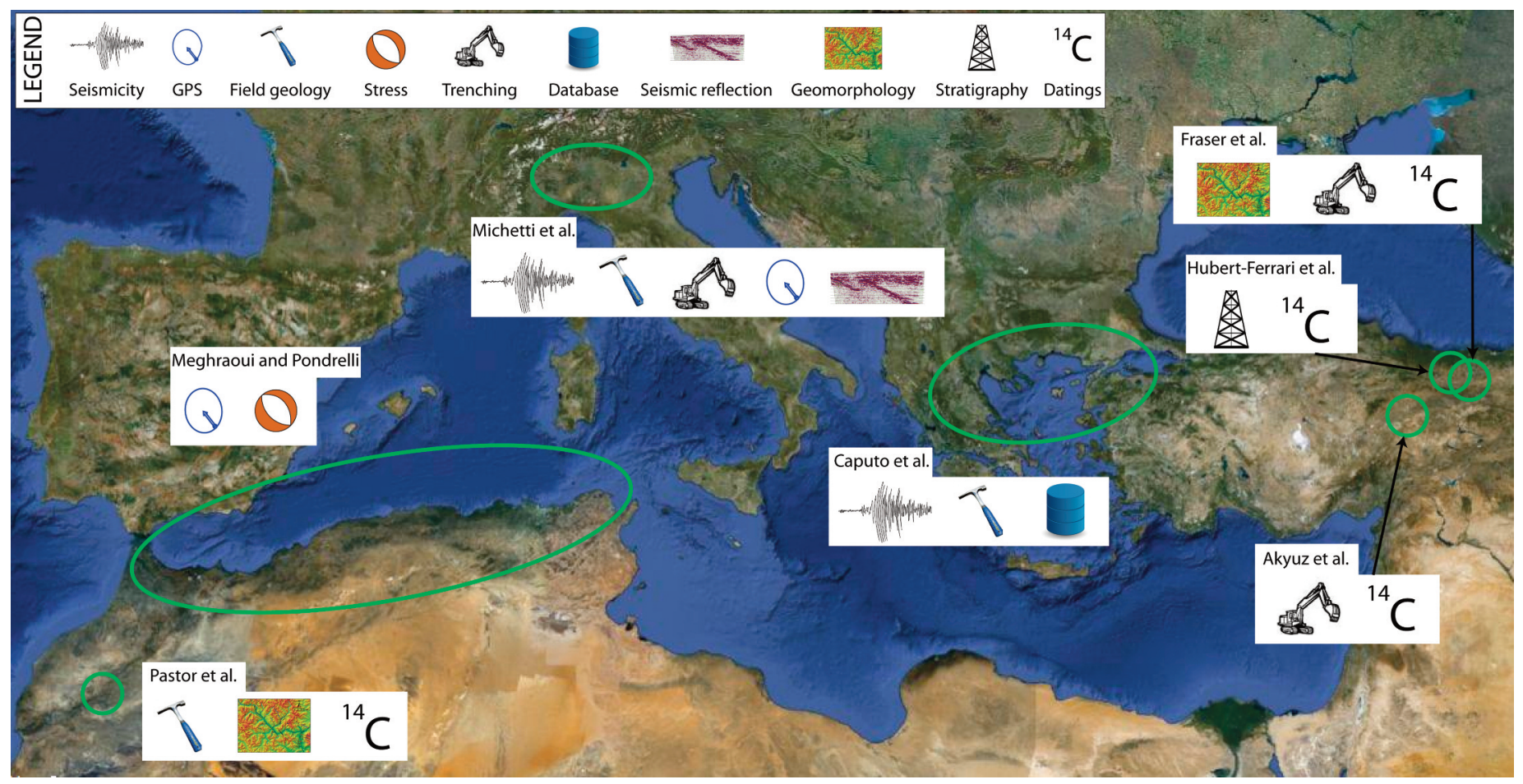

Akyuz et al.

Akyuz et al. applied a detailed geomorphic analysis and paleoseismological investigation, based on aerial photos interpretation and field survey, on a poorly known "probably active fault" in Central Anatolia (Turkey), the Tecer Fault. At present, the debate on the amount and location of active deformation in the Central Anatolian block is a "hot" issue with several different interpretations but little data. Local instrumental and historical seismicity is quite limited and no evidence for medium-strong earthquakes exists. This work is intended to furnish an original contribution a) to understand the present seismic deformation in the upper crust in the northeastern portion of the Central Anatolian Fault System, b) to the modern regional seismic hazard estimations. The authors defined the location, geometry and kinematics of the Tecer Fault, that is imaged as a $45 \mathrm{~km}$-long, pure left-lateral tectonic structure showing up to tens of meters of cumulative offset 
on geomorphological features. The paleoseismological results suggest the occurrence of Holocene surface faulting events (separated by some thousands of years), a fault activity in the order of $1 \mathrm{~mm} / \mathrm{yr}$ and earthquakes with maximum expected magnitude of about 7 .

\section{Caputo et al.}

Caputo et al. present the state of the art of the Greek Database of Seismogenic Sources (GreDaSS) for northern Greece. This contribution is part of a European-scale project (Share: Seismic Hazard Harmonization in Europe) and North Greece is presented as pilot area thanks to its good level of completeness in terms of seismogenic sources and their associated metadata. It is a continuously updatable database of all faults activated in historical and instrumental periods as well as of those structures considered active based on geological, geomorphological and geophysical investigations. The database provides consistent and uniform information on the main seismotectonic parameters, like fault location, geometry and kinematics together with comments, open questions, figures, relevant literature etc. using both published and original data. Sources considered not capable of producing at least a $M \geq 5.5$ earthquake were excluded from the database. Apart from the various SHA applications, this database could also be used to better understand and model the seismotectonic setting of the broader Aegean Region.

\section{Fraser et al.}

Fraser et al. applied geomorphic analysis, classical paleoseismic trenching, and radiocarbon dating coupled with Bayesian ordering-constrained modeling. They report paleoseismic results from a trench situated near the center of the segment of the North Anatolian fault that ruptured in the 1939 Erzincan earthquake, in a $\sim 150-\mathrm{km}$ wide gap between previous studies. The investigation focused on determining an as long as possible record of the timing of paleoearthquakes, which involved investigating trenches perpendicular to the fault in locations with regular and relatively continuous sedimentation and a persistent apparent vertical displacement. This in turn involved a thorough geomorphic analysis of the area, and excavation of test pits. Their main trench was situated in fine-grained inter-fan deposits at the base of the faultbounded side of an elongated ridge. These fine-grained deposits alternate with wedge-shaped gravel units that are interpreted as colluvial wedges, but not in the classical sense, i.e. they are interpreted to have formed by widespread slope failure due to seismic shaking, rather than by fault-scarp retrogression. This interpretation is corroborated by some upper fault terminations, and by correlation of the two most recent events with the more classical evidence found in smaller trenches nearby. With this strategy, the amount of offset associated with each event cannot be determined, but this is traded off against a longer record of six earthquakes in this case. The entire trench sequence was sampled for radiocarbon dating, which allowed constructing an ordering-constrained Bayesian model to determine probability density functions of sample ages, event ages, and inter-event times. The event timing was then compared with paleoearthquake chronologies obtained at three other sites on the rupture segment, in order to determine whether previous earthquake ruptures had the same extent as the 1939 Erzincan earthquake. They found evidence for only one paleoearthquake in A.D. 499 that ruptured the entire segment. Their results thus suggest that the segment does not behave the same during each seismic cycle, which results in variable rupture lengths, and hence variable magnitudes.

\section{Hubert-Ferrari et al.}

The Hubert-Ferrari et al. paper presents an interesting paleoseismic record derived from a multidisciplinary analysis of cores collected in a lake located in the Gölova Basin, along the eastern portion of the North Anatolian Fault. The 1939 earthquake segment fault runs across this shallow lake, namely the Aşağıtepecik Lake, and produced at the surface a coseismic right-lateral offset of more than $6 \mathrm{~m}$.

The three cores presented were collected in 2006 and 2007 and underwent different types of analysis performed to characterize both the continuous sedimentation and potential high-energy layers related to important seismic activity of this segment of the North Anatolian Fault. After discussing the results obtained from X-Ray, grain size, magnetic susceptibility, bulk mineralogy, Total Organic Content and major elements by X-Ray Fluorescence, the authors present their interpretation of the environmental change found in the cores as well as of the four "disturbed" layers interrupting the common lacustrine organic rich sedimentation. The mineralogical, organic, textural and structural characteristics of these peculiar four deposits imply resuspension, and reworking of lake sediments together with an increase in sedimentary runoff, all interpreted as potentially triggered by earthquake shaking. Chronological constraints consist of new radiocarbon ages, previously published $210 \mathrm{~Pb}-137 \mathrm{Cs}$ data and use of a reference varve record. The resulting age model suggests that three "disturbed" layers may well fit the occurrence of 1939, 1668 and 1254 regional historical large earthquakes, underlining the high, but not yet fully explored potential of paleoseismological studies in lacustrine environments. 


\section{Meghraoui and Pondrelli}

This paper focuses on the Gibraltar-Sicily section of the Africa-Eurasia plate boundary. In particular, the authors present a synthesis of the active tectonics of the northern Atlas Mountains that are among the most active zones in the Mediterranean region, as large and moderate-sized shallow seismic events were recorded in the last decades along this plate boundary (M 7.3 El Asnam 1980, M 6.9 Boumerdes 2003, M 6.4 Al Hoceima 2004). The first part of the paper is devoted to a review of the existing geological and geophysical data set: local and regional deformation rates in North Africa are estimated from fault kinematics, focal mechanisms and GPS. Neotectonic structures and significant shallow seismicity indicate that coeval east-west trending right-lateral faulting and NE-SW thrust-related folding result from the oblique convergence at the plate boundary, and form a transpressional system. The strain distribution obtained from fault-fold structures and $\mathrm{P}$ axis directions of focal mechanisms, and the geodetic convergence show that shortening and convergence directions are not coaxial. On this basis the Authors present a new interpretation of the Africa-Eurasia plate boundary by proposing a kinematic model controlled by distributed and partitioned transpressional tectonics that may account for the main tectonic processes along the plate boundary in North Africa.

\section{Michetti et al.}

This paper deals with the seismic hazard of the Po Plain, one of the most densely populated and developed areas of Europe, hosting a substantial portion of the Italian industrial production, with many critical infrastructures and a number of plants that pose high environmental risk. This area has always been considered to have moderate seismic hazard on the basis of a relatively infrequent occurrence of significant seismicity and on the dearth of ad hoc research on the geology of earthquakes in the perspective of seismic hazard assessment. With their analysis and considerations the authors try to put in evidence that the seismic hazard of this region is underestimated. This important issue is described using published and new data that include information on the historical and instrumental seismicity, subsurface information from industrial exploration, seismic reflection profiles, analysis of GPS data, field mapping and paleoseismological investigations. The Authors focus on four case studies, two located in the Western South Alpine front (Brescia area and Insubria region), and two along the Northern Apennines front (Torino-Monferrato area and Mirandola structure). The data presented in this paper strongly suggest that the level of earthquake hazard in the Po Plain is comparable to that existing in the Apenninic range, at least in terms of maximum expected magnitude. This general conclusion was dramatically confirmed by the occurrence of the M 5.9 May 20, 2012 Emilia earthquake, which arguably ruptured the Mirandola source, hence strengthening the issue of the significant seismogenic potential associated to the Po Plain structures.

\section{Pastor et al.}

Pastor et al. investigate the Quaternary deformation in the Ouarzazate Basin (Atlas range, Morocco). They focus on the southern orogenic front of the Atlas, a low deformation area with very little seismicity but where some Quaternary deformations have been defined, mostly along the frontal part of the Atlas. Compressional structures have affected there the best preserved fluvial terrace sequence in the Atlas. The authors obtain long-term deformational rates by leveling precise structural cross-sections across the area, and obtain Quaternary slip-rates from the study of the terraces benefiting from their recently published results on numerical dating in these recent deposits. They show how the Quaternary rates almost double those since the onset of the structure, discuss the influence of the erosional denudation of the basin as a possible cause for it, and suggest the seismogenic potential of some faults in the area. In recent years, active tectonics analyses of areas under slow deformation rates have revealed dangerous and hidden seismogenic faults in many regions around the world. This paper is a good example of how to characterize such faults by using alternative techniques.

\section{Acknowledgements}

We acknowledge the many reviewers who contributed to the quality of this special volume with critical readings and constructive comments, the AoG Editor in Chief Edoardo del Pezzo for his encouragement and Anna Grazia Chiodetti and the Editorial Office of the journal for the prompt and continuous technical support.

(C) 2012 by the Istituto Nazionale di Geofisica e Vulcanologia. All rights reserved. 